\title{
Oscillation of The Per Capita Growth Rate
}

\author{
Adil Mahmood \\ Njlaa I. Tawfiq \\ Hussain A. Mohamad
}

**

Dale of acceptance $11 / 10 / 20(0)$

\section{Abstract}

In this paper, equations of the per capita growth rate are considered. Sullicient conditions for Oscillation of all solutions are oblained. The asympletic behavior of the nonoscillatory solutions is investigated.

Keywords. The per capita growh rate, oscillation, nonoscillatory, nettral diflerential equations.

\section{Introduction.}

In this paper we discussed the ." Oscillation of the per capila grouth "ale" which is a delay differential equation transformed to a neutral delay dilferential equation of hirst

order. Consider the classical delay logistic equation [10].

$N^{\prime}(l)=r N(t)\left[1-\frac{N(\tau(t))}{K}\right]$,

which investigated in this paper, the per capita growth rate

$h(t)=\frac{N^{\prime}(t)}{N(t)}=r\left[1-\frac{N(\tau(t))}{K}\right]$,

capila growth rate associated with density dependence, and $h_{1}(t) \ldots \cdot \frac{N^{\prime}(\tau(t))}{N(\tau(l))}$, is the per cappitat growth rate associaled with per capita growh rate at line $r(f)$. This leads to the neutral delaty dirierential equation N(t):

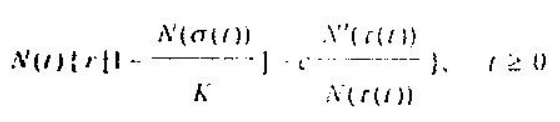

Where

where $N(t)$ denotes the density of population at time $t, r$ is the growth rate and $K$ is the carrying capacity of the environment. $\tau(t)$ denotes the feedback mechanism, which responds to changes in the size of the population. In [10] assumed that the per capita growth rate $h(t)$ is given by $h(t)=h_{\sigma}(t)-h_{r}(t)$, where $h_{\sigma}(t)=r\left[1-\frac{N(\sigma(t))}{K}\right]$, is the per $r, K \in(0, \infty), \quad \sigma(l),(l) \in(\{|| 0, \infty) ; \mid 0, \infty) \mid$, and $\therefore($ w, s.). An altemative. model may be oblained by considering the growth rates rather than the per capita growth rates, this leads to the neutral delay differential equation $N^{\prime \prime}(1)=$

$$
N(t)+1) \frac{N(w(t))}{\kappa}, \frac{N(r(t))}{\kappa},, \quad t \geq 0
$$

Dr.-Prof-Math. Dept.-College of Ibn Al- Initihum

"Dr.-Math. Dept.-College of Science-University of Baghdad

"* MSC.-Math. Dept.- College of Science-University of Baghthat 
with Eq. (1) and (2) one associates an initial condition of the form

$N(l)=\phi(t), \quad-\gamma(l) \leq t \leq 0 \quad$ with $\gamma(t)=\max \{\sigma(t), \tau(t)\}, \quad$ where the initial function $\phi(t)$ satisfy the following condition :

$\phi(t) \in C\left[[-\gamma(t), 0] ; R^{+}\right], \quad \phi(t)>0 \quad$ for $-\gamma(t) \leq t \leq 0$

and $\phi(t)$ is absolutely continuous with locally bounded derivative on $-\tau(t) \leq t \leq 0$. By uniqueness theorem the initial value problem (1) and (3) has unique solution which exists and remains positive on $[0, \infty)$. The same is true for the initial value problem (2) and (3). By introducing the change of variable $\quad x(t)=\ln \frac{N(t)}{K}$ Eq. (1) and

(2) transformed to

$$
\frac{d}{d}[x(t)+c x(r(t))]+r\left[e^{x(\sigma(t))}-1\right]=0, \quad t \geq 0
$$

And

$$
\frac{d}{d t}\left[x(t)+c\left[e^{x(t(t))}-1\right]\right]+r\left[e^{x(\sigma(t))}-1\right]=0, \quad t \geq 0
$$

respectively. In this paper we considered the oscillatory properties of the positive solutions of equations (1) and (2) about the unique positive steady state $K$. Clearly;

every positive solution of (1) and (2) oscillatory about $K$ if and only if every solution of (4) and (5) oscillates aboul zero. We can extunded liy.(4) and (5) by making $r$ is a function of $l$ and so Eq. (4) and (5) can be wrillen in the form

$\frac{d}{d t}[x(t)+c x(\tau(t))]+r(t) f(x(\sigma(t))=0, \quad t \geq 0$

and

$\frac{d}{d t}[x(t)+c f(x(r(t))]+r(t) f(x(\sigma(t))=0, \quad t=0$ respectively,

where $r(l) \in\left(\left(\left[t_{0}, \infty\right) ;(0, \infty)\right)\right.$. We will establish necessary and sulficient conditions for the oscillation of every solution of lic. (4') and sufficiont conditions for the nonoscillatory solutions al Eq. (4') to converge to zero als $t \rightarrow \infty$.

\section{Main Results.}

In this section we will obtain the sufficient conditions for the oscillation of every solution of Ly.(4'), where the function $f$ satislies the condition $x f(x)>0$, where

$x>0$, and sullicient conditions for the nonoscillatory solution ol equation (4') to converge to 0 . We deline the finction $\quad z(1) \cdots x(t)+c x(r(t))$. Then equation (f') will bo as lollows:

$$
z^{\prime}(l)=-r(l) /(x(\sigma(l)))
$$

Now we prove the lollowing theorems.

Theorem 1. Suppose that, $f$ is an increasing function, $0 \leq c<1, r(t)>0, r(t)>t$ for $t \geq t_{0}$ and

$$
\int f(x) d x=\infty
$$

Then all solurions of equation (4') are oscillatory.

Proof. Asstme that $x(t)$ is a nonoscillatory' solution of equation (4') and $x(t)>0$ for large $t$, for $t_{1} \geq t_{0}$ we have $x(\sigma(t))$ and $x(\tau(t))$ are positive for $t \geq t_{1} \geq t_{0}$, and $f$ is an increasing function. ITwen by oquation (6) we have onty the case $z^{\prime}(l) \leq 0, \quad z(l)>0$ w discans.

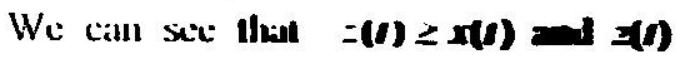
is dicterising. whan kets to $z(r(I)) \leq z(I) \leq x(t)+c z(c))$

From the lase $z(r(t))(1-c) \leq x(I)$. 
that is $z(\tau(\sigma(t)))(1-c) \leq x(\sigma(t))$ so, equation (6) will be

$$
z^{\prime}(t)+r(t) f(z(\tau(\sigma(t))))(1-c) \leq 0
$$

Integrating the last inequality from $t_{\text {, }}$ to $t$

$$
z(t)-z\left(t_{1}\right)+\int_{l_{1}}^{f} r(s) f(z(r(\sigma(s))))(1-c) d s \leq 0
$$

But $f$ increasing so

$$
z(l)-z\left(l_{1}\right)+f\left(z\left(\tau\left(\sigma\left(l_{1}\right)\right)\right)\right)(1-c) \int_{l_{1}}^{1} r(s) d s \leq 0
$$

As $t \rightarrow \infty$ we get a contradiction. Then $x(t)$ can not be eventually positive and in the same way we can proof that $x(t)$ can not be eventually negative, and so $x(t)$ can not be nonoscillatory.

Theorem 2. Suppose that, $f$ is an increasing function, $c \geq 0, r(t)>0$ for $\iota \geq t_{0}$, and

(7) holds. Then all solutions of equation (4') are oscillatory.

Proof. Let $x(t)$ be an eventually positive solution of equation (4'), so we can choose $t_{1}$ such large that $x(\sigma(t))$ and $x(\tau(t))$ are positive for $t \geq t_{1}$, we have $f$ is an increasing function. By equation (6) we can see that $z^{\prime}(t)<0$ then we have only the possible $z(t)>0, \quad t \geq t_{1} \geq t_{0}, \quad$ to discuss.

Integrating equation (6) from $t_{1}$ to $t$

$$
\begin{aligned}
& z(t)-z\left(t_{1}\right)= \\
& -\int_{t_{1}}^{t} r(s) f(z(\sigma(s))) d s \leq-f\left(z\left(\sigma\left(t_{1}\right)\right)\right) \int_{t_{1}}^{t} r(s) d s
\end{aligned}
$$

as $t \rightarrow \infty$ we get $\lim _{l \rightarrow \infty} z(t)=-\infty$, which is a contradiction .

Remark 1. According to the two Theorems (1) and (2) we can conclude that all solutions of equation (1) are oscillatory about a unique positive steady state $K$ under the conditions of these theorems.

Theorem 3. Suppose that $c \geq 0, \quad r(t)>r>0$, and $|f(u)| \geq a|u|, \quad a>0$

for $t \geq t_{0}$. Then every nonoseillatory solution of equation (4') tends to zero as $t \rightarrow \infty$.

Proof. Assume that $x(t)$ be an eventually positive solution of equation $\left(4^{\prime}\right)$, and $x(\sigma(t))>0, x(\tau(t))>0$, for $t \geq t_{1} \geq t_{0}$. Then we have only the case $z^{\prime}(l)<0, \quad z(l)>0$,

to discuss, which means $z(t)$ is bounded, then there exists $M>0$ such that $z(l) \leq M$, this implies that $x(t) \leq M$, let

$\lim _{t \rightarrow \infty} z(t)=L \geq 0$,

suppose that $L \neq 0$ then $L>0$. Integrating equation (6) from $t_{1}$ to $\infty$ we get

$z\left(t_{1}\right)-L=\int_{t_{1}}^{\omega} r(s) f(z(\sigma(s))) d s$

by (8) we get

$$
z\left(t_{1}\right)-L \geq r a \int_{t_{1}}^{\infty} x(\sigma(s)) d s
$$

that means $x(l) \in L_{1}\left[l_{1}, \infty\right)$, since $z(l)$ is bounded, we conclude that $z(t) \in L_{1}\left[t_{1}, \infty\right)$

by integrating the inequality $z(l) \geq I,>0$. from $t_{1}(1) \infty$ we get $\int_{t_{1}}^{\infty} z(s) d s \geq L \int_{i_{1}}^{\omega_{1}} d s$,

which leads to

$$
\int_{i_{1}}^{\infty} z\left(s^{\prime}\right) d s=\infty \text {, }
$$

and this is impossible since $z(t) \in L_{1}\left[t_{1}, \infty\right)$ then $\lim _{\operatorname{lin}} z(t)=0$ but $\quad z(1) \geq x(t)$, and so limstup $x(t) \div 0$ which implies that $\lim _{l \rightarrow \infty} x(t)=0$. The prool is complete.

Remark 2. According to Theorem (3) we can conclude that every 
nonoscillatory solution of equation (1) tends to a unique positive steady stale $K$ as $t \rightarrow \infty$, under the conditions of this theorem.

\section{Reference}

1. Gy.ri, I. and Ladas, G. 1901 "Oscillation Theory of Delay Differential Equations"

Clarendon Press-Oxford.

2. Ladde, G. S., Lakshmikantham V. and Zhang B. G. 1987 "Oscillation Theory of Differential Equations With Deviating Arguments" New York And Basel.
3. Mohimat, Ilussain and Olach Rudoll 1998 "Oscillation of Second (Mrder Linear Neutral Differential Equation" Proceedings of the International Scientitic contirence of Mathematics, jilina PP 195-201.

4. Mohimad, Hussain 1999

"Oscillation (of" $\mathrm{N}$-th Order Linear Diflerential Lquations of Neutral Type" Proceedings of The International Scientific Conference Of Mathematics. Siam Herlany, PP' (130-135).

5. Olach. R. 1995 "()scillation of Differential liquation Ol Neumal Tyре" Hirushima Math. J. 25, 1-10.

\section{التذبذب في سعة معلدل النمو السكاني}
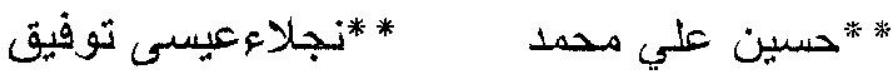

عادل محمود

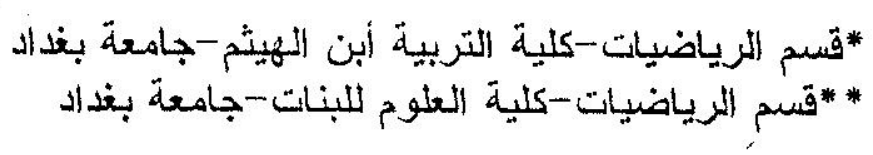

المستخلص ان المعادلة النتباطؤ يـالتلو جستيتسعرفة بالثكل

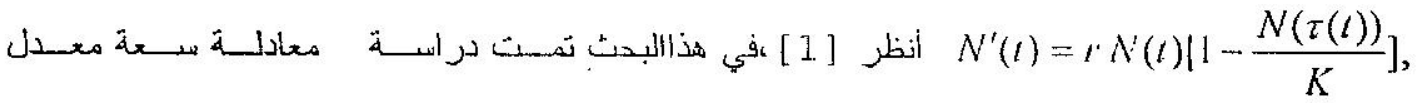

النمو السكاني ,

حيث اعطيت بعض الشروط الكافية لتذبذب حلول هذه المعادلنو التي تمثل الكثافة|لسكانية (l)

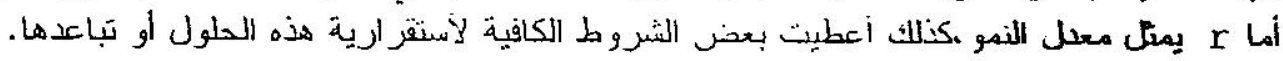

